\title{
Sichuantextile Park Present Situation and the Future Development Strategy
}

\author{
Yinfeng Liu*
}

Chengdu Textile College, Chengdu, China

*Corresponding author. Email: 278312854@qq.com

\begin{abstract}
The article constructively puts forward some countermeasures to revitalize Sichuan textile park. Firstly, the development status of Sichuan textile parks is analyzed. In view of the existing problems such as unreasonable industrial structure, insignificant advantages of elements and resources, and homogenized development, countermeasures and suggestions are given from the aspects of park planning, industrial chain perfection, resource advantages play, transformation and upgrading. The innovation of this paper lies in the investigation and analysis of the key textile parks in Sichuan.
\end{abstract}

Keywords: Textile Park, Development status, Problem, Development strategy, Sichuan.

\section{四川纺织园区现状与未来发展策略}

刘银锋*

成都纺织高等专科学校, 成都, 中国

*通讯作者. 邮箱：278312854@qq. com

\section{中文摘要}

文章建设性地提出了四川纺织园区重新焕发生机的应对之策. 首先分析了四川纺织园区发展现状, 针对目前存 在的产业结构不合理、要素资源优势不明显、同质化发展现象等问题, 从园区规划先行、产业链完善、资源优 势发挥、转型升级等方面给出了对策建议. 文中对四川重点纺织园区的调研分析是本文的创新所在。

关键词: 纺织园区; 发展现状; 问题; 发展策略; 四川.

\section{1. 引言}

在国内国际双循环新发展格局背景下, 纺织服装 产业已悄然进入新发展阶段, 纺织服装产业园区如何 增长动力和创新活力, 形成新的集聚效应, 更好地发 挥园区在行业高质量发展中的示范引领和带动作用, 已成为行业必须思考和面临的问题. 四川纺织产业在 全国具有一定的竞争力, 产业园区和集群发展态势良 好. 本文通过分析四川纺织园区发展存在的问题并相
应提出未来发展策略, 可为纺织产业园区和集群发展 研究提供经验借鉴和规律探索.

\section{2 . 四川纺织园区发展现状}

四川作为人口大省,纺织产业正在加速发展,目前 已形成了一大批纺织服装产业园区和集群,如成、德、 绵的服装、家纺产业集群，南充丝绸纺织产业集群， 遂宁棉纺织产业集群,达州荁麻纺织基地，广安的牛 仔园,雅安芦山的包覆纱、乐山井研的纺织工装面料、 
屏山的生物基纺织产业以及宜宾、自贡的西部化纤纺 织原料基地等,全省纺织工业已逐步形成“产业规模持 续增强、产业体系更趋完善、产业集聚逐步提升、特 色优势更加明显、创新能力不断提高”的基本格局.其 发展现状呈现出以下特征:

\section{1. 把纺织园区规划建设作为一项重要举措}

在四川纺织产业发展过程中, 部分发展较好的地 区把园区规划作为一项重要举措, 引导和吸引企业向 园区集中. 聘请成都纺织高等专科学校、四川纺织科 学研究院等科研院所及行业专家编制纺织园区产业 发展规划, 如四川彭州、广安、屏山、芦山等纺织产 业发展规划已落地实施. 调研发现, 这些园区起步水 平高, 发展势头普遍好于其他没有相关规划的园区.

\section{2. 园区纺织产业链貌合神离}

全川纺织服装产业园区和集群间空间距离并不远, 但是, 由于受制度变迁、市场、本地企业自身实力不 足等关键因素的影响, 产业链各环节在本地的耦合度 不高, 产业链处于一种貌合神离的状况. 全省除蚕茧 丝绸与菅麻织布产业链本地耦合运行度较高外, 其他 园区产业链长期低耦合度运行. 全川印染业和服装业 主产品销售额比重仅占全行业的 6\%和 13\%; 化纤业包 括新型化纤品种较为单一, 产业用纺织品总量较低; 服装、家纺业发展受面料、辅料、祄布、拉链、纽扣、 缝㧅线配套不足的制约, 均未形成完整的产业链.

\section{3. 四川纺织资源未能在园区有效利用}

四川不仅有丰富的桑䖯丝、棉、纺、人造纤维、 生物基纺织纤维、芳麻等纺织原材料资源, 而且一些 资源优势还明显. 全川拥有一大批技术熟练的纺织产 业工人, 拥有近 700 万服装生产工人, 但只有不到 10\% 的工人在本地就业, 绝大部分均在外打工. 这些资源 都没能很好地利用, 没有让其在各园区或纺织产业发 展中发挥该有的作用.

\section{4. 四川六大地区品牌产品竞争力强, 但知名 品牌并不多}

四川省六大地区品牌产品（丝织品、桑蚕丝、棉 混纺布、人造纤维、工装、苦麻布)在全国的竞争力 较强,如生丝产量占全国 23\%, 在国内省市中居第 2 位,化纤产量占全国的 $1.58 \%$, 在国内省市中居第 5 位. “丝丽雅” 是中国驰名品牌, 许多技术全球领先; “琪 达”服装、“宝珍”丝绸是中国驰名商标;“雷迪波尔”、 “欧度”、“四川依格尔”、“巨人树”等品牌在西部地区 乃至全国也有了一定的知名度. 全行业拥有四川名牌 产品 41 个,四川著名商标 30 余个.但横向比较, 国内 知名品牌并不多,国际名牌几乎没有.

\section{3. 四川典型纺织园区规划调研}

\section{1. 屏山、三台、遂宁纺织园区}

屏山纺织工业园区作为宜宾千亿纺织产业重要组 成部分,以生物基纺织为主导产业,计划到 2025 年实 现产值达 400 亿元.四川三台纺织园区已初步形成了 纺纱-织布-印染-鞋服加工等完整的纺织服装产业链 条,到 2025 年,产业功能区产业规模将达到 500 亿元. 遂宁纺织基地已形成棉纺织、丝纺织、化纤纺织、印 染、针织、服装、纺织机械等门类齐全的工业体系,“十 四五”目标产值 500 亿元.

\section{2. 其他纺织园区}

2025-2030 年期间, 四川规划目标 300 亿元的纺织 园区包括彭州家纺产业园、芦山纺织产业园、南充市 丝纺服装产业集群等;规划目标 100 亿的园区包括四 川富顺纺织服装产业园、广元纺织服装科技产业园、 广安西部牛仔城、乐山井研县纺织服装产业园等以及 若干 100 亿元以下分布在新都、金堂、射洪、大英、 安居、自贡、大竹、简阳等地各具特色的纺织园区.

\section{4 . 四川纺织园区产业发展存在的问题}

\section{1. 产业结构单一，产业链不完整}

全川各纺织园区发展特征: 前纺大而不强, 后纺弱 且不优; 高品质、高附加值的产品比重较低; 服装主要 以职业装为主, 产业结构比较单一. 各纺织园区发展 各有侧重: 遂宁以高档服装面料和高档家纺面料等纺 织品为发展重点, 广安以牛仔服装发展为主, 乐山井 研以纺织工装面料为主, 彭州以家纺、服装为主, 芦山 以功能性工装面料包覆纱为发展重点; 南充都京丝纺 服装工业园以桑、䖯、丝、绸、染、服产业链为发展 重点等等. 但产业链连接都不紧密, 无法支撑整个园 区和集群的发展.

\section{2. 园区要素资源优势已不明显}

全川纺织园区在要素资源方面,水电气资源价格有 一点优势, 但国家电价改革, 各地方执行标准不一, 造 成电力成本偏高; 在土地资源上,无论是土地指标还是 土地价格,与中部比已没有优势可言.更关键的是,四 川省劳动力价格与劳动效率大致都是东部的 $3 / 4$. 同时, 国家出台了对中小企业金融支持政策,但地方中小银 行在执行上没有到位,企业贷款仍然难.

\section{3. 产业园区同质化发展现象明显}

全川纺织仍以棉纺织初加工为主,服装中低端产品 占比大,产业的技术含量比较低,产业深加工的比重小, 附加值不高.产业在信息化、智能化、网络化等技术 
改造升级,智能车间、智能工厂建设方面与东部发达 地区差距明显.虽然各纺织园区产品各有侧重,但同质 化发展现象突出,特色不明显.部分纺织园区只注重企 业的聚集,不注重配套企业引进,不注重产业与城市、 生活、生态的融合发展.

\section{5 . 四川纺织园区产业发展对策}

\section{1. 规划先行, 完善产业链}

全川纺织园区产业发展重点不同, 具有完整产业 链的园区几乎没有, 导致本地产业链及链上企业不能 同舟共济形成共赢格局, 而且长期处于背负高物流成 本运行状况而无法提高竞争力. 因此, 各园区要在产 业链上下游方面下功夫, 吸引更多的配套企业入驻园 区, 规划先行, 科学发展.

\section{2. 充分利用并发挥好资源优势}

四川的蚕茧、拦麻、竹子等生物基纺织资源有比 较优势; 四川还是一个人口大省、多民族省份; 如今还 是汉服第一城; 历史文化洲源流长、博大精深. 全川纺 织园区应充分利用和发挥好这些独特的资源优势, 发 展纺织服装特色产业, 比如可以开发竹纤维原料, 水 刺无纺布, 卫生防护产品, 产业用纺织品等.

\section{3. 坚定转型升级、创新驱动发展路径}

如今, 东部纺织服装产业正在大力调整产业结构 和转变发展方式, 将加大分享国内需求扩大红利的能 力. 为此, 对西部投资是必然选择. 这为西部包括四川 跨越式发展纺织产业提供了重要动力, 也是四川纺织 产业转型升级、创新驱动发展、适应国际国内双循环 战略的最好机遇期. 全川各园区要抓住机遇, 推进产 业加快技术改造升级, 建设一批有示范带头作用的智 能车间、智能工厂; 加强纺织服装创意设计平台建设, 加强品牌宣传推广, 不断提升传统纺织服装品牌的影 响力和竞争力.

\section{4. 走特色发展之路, 才能赢得竞争力}

目前,四川纺织服装产业不具备全面开花式的发展 条件,但是生态、环保、低碳资源富集,并且拥有较好 产业基础和区域产品品牌, 以及丰富多彩的文化资源. 因此,在铸就产业核心竞争力的过程中应把重现丝绸、 亖麻、蜀锦、蜀绣、民族服装服饰等传统优势产品的 辉煌作为突破口, 打造四川品牌, 走特色发展之路. 注 重产业向微笑曲线两端跃升,以成都为依托,做好时尚 产业和传统产业的结合, 驾驭成都充分国际化东风,大 力开发新材料,大力发展服装、服饰、家纺特色文化 创意产业等.

\section{6. 结论}

四川纺织园区和集群呈现初步发展态势, 未来要 重新焕发生机,必须更新发展理念和发展思路，规划 先行、科学发展, 充分利用和发挥蒠麻、蚕丝、竹等 生态资源优势, 走转型升级、特色发展之路, 发挥园 区的示范引领和带动作用, 推动四川纺织行业高质量 发展。

\section{REFERENCES}

[1] Textile and Clothing Industry Cluster (Park) Development Conference[EB/OL]. [2021]. https://www.xianjichina.com/news/details_103146. html

[2] Chengdu Textile College. Development Planning of Sichuan Lushan Textile Industry [M]. Chengdu: Chengdu Textile Institute 2020.

[3] Sichuan Statistics Bureau. Sichuan Statistical Yearbook [M]. Chengdu: Sichuan Statistics Bureau, 2020

[4] Chengdu Textile College. Development Planning of Bio-based Textile Industry in Pingshan, Sichuan [M]. Chengdu: Chengdu Textile Industry 2019.

[5] Liu Yin-feng Logistics Problems and Countermeasures Based on Industrial Clusters -A Case Study of Pengzhou Home Textile and Clothing Industry [J]. 2017 4th International Conference on Education Reform and Modern Management (ERMM) 2017).

[6] Liu Zeren, Zhong Zhen, Liu Yinfeng: Suggestions on the Development of Textile and Apparel Industry in Sichuan Province [J]. Economic Research Review, 2014(8) 